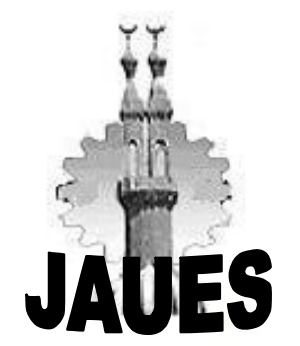

Journal of Al-Azhar University Engineering Sector

Vol.16, No. 58, January, 2021, 34-48

\title{
A DECENTRALIZED CHARGING STRATEGY FOR PLUG-IN- ELECTRIC VEHICLES IN PARKING LOTS
}

\author{
Muhammad Said ${ }^{1}$, Walid A. Omran ${ }^{1}$ and Hossam E. A. Talaat ${ }^{2}$ \\ ${ }^{1}$ Department of Electrical Engineering, faculty of Engineering, Ain Shams University, \\ Cairo, Egypt. \\ 2 Department of Electrical Engineering, faculty of Engineering, Future University in \\ Egypt, Cairo, Egypt. \\ *Corresponding Author E-mail: eng.muhammadsaid@gmail.com
}

\begin{abstract}
:
Recently, the penetration level of plug-in electric vehicles (PEV) increased considerably in several countries. This increase has led to the construction of parking lots (PLs) to facilitate the charging of these vehicles. However, the uncontrolled charging of PEVs might result in several technical problems in the electric network. In this paper we propose a decentralized smart charging scheme which seeks to minimize the cost of charging of PEVs according to the optimal response of each electric vehicle to the day-ahead charging prices of the PL.

Two alternative tariffs are explored; the real time pricing (RTP) and time of use pricing (TOU). The smart charging is compared with the uncontrolled charging using the IEEE 15bus distribution system over a 24-hour period considering uncertainties of the driving behavior of PEVs. The problem is formulated as a mixed integer linear programming (MILP) optimization problem and is solved in MATLAB using the salp swarm algorithm (SSA) technique. The simulation results which compared with results from particle swarm optimization (PSO) technique show that, compared with uncontrolled charging, smart charging scheme can avoid asset overloading, and displace most charging to valley hours.
\end{abstract}

\section{KEYWORDS: Plug-in Electric Vehicles, Salp Swarm Algorithm, Particle Swarm} Optimization, Smart Charging, Demand Side Management, Parking Lots

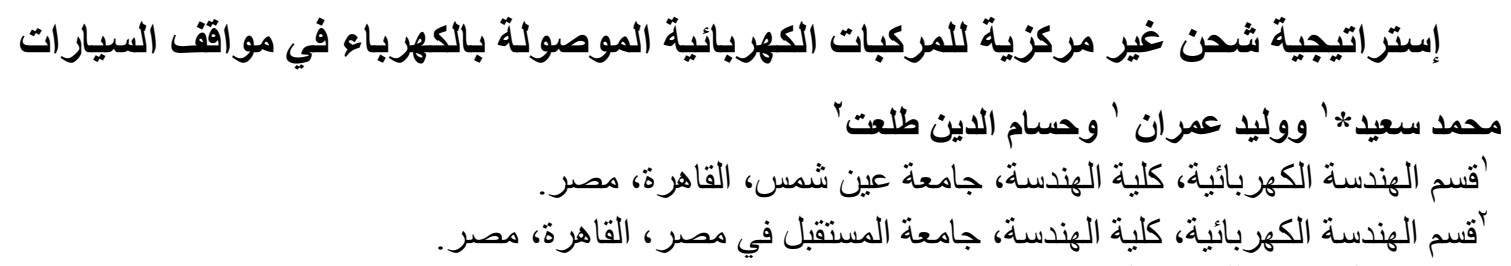

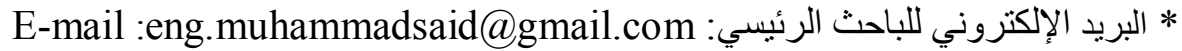

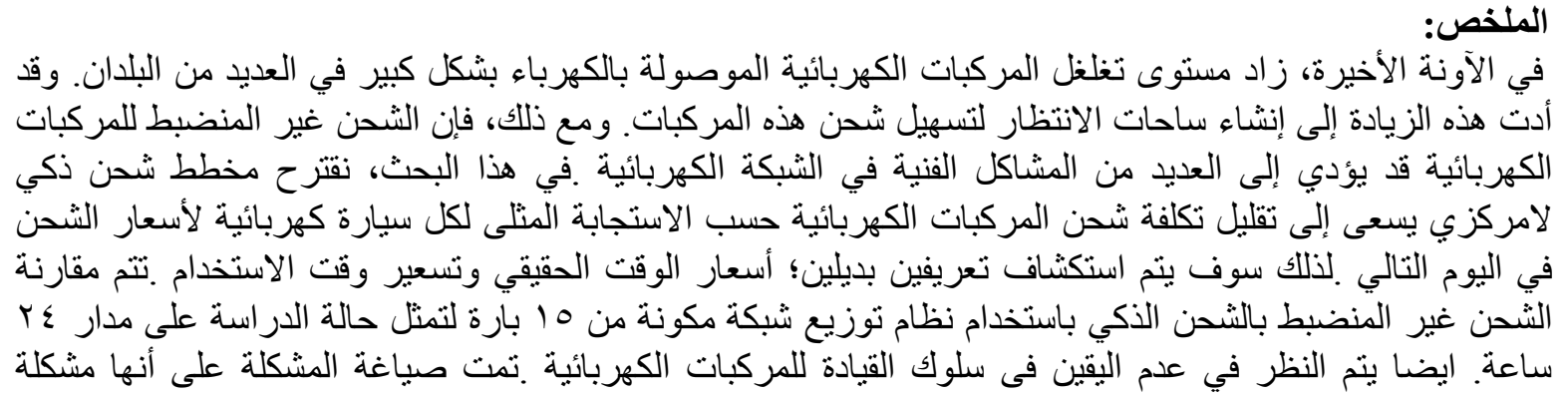




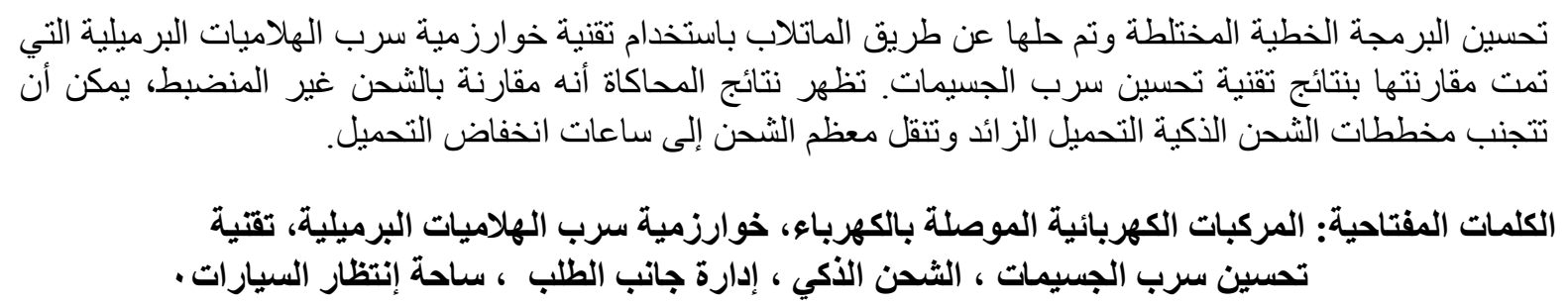

\section{INTRODUCTION}

The widespread use of PEVs can significantly reduce fossil fuel usage, and hence, harmful gas emissions. Many countries encourage the usage of PEVs due to their environmental and economic benefits (Rajakaruna, et al., 2015) (Annual Energy Outlook 2020, 2020). Figure 1 shows the projected PEVs world market share during the period 2018-2030 (Bloomberg, 2019), where it is expected to reach $40 \%$ of the vehicles sales in 2030.

PEVs require frequent charging from the electric network which can be achieved by two charging modes. The first mode is the uncontrolled charging where the PEVs charge energy whenever needed at parking lots (PLs) or in the households. The second mode is the smart charging, where PEVs adapt their charging profile by responding to energy pricing signals. The uncontrolled charging mode of PEVs might lead to several operational problems; including increased network losses, overloading, unbalancing of load and excessive voltage drop (Shareef, Islam, \& Mohamed, 2016) (Yong, K.Ramachandaramurthy, Tan, \& N.Mithulananthan, 2015) (Hoog, Alpcan, Brazil, Thomas, \& Mareels, 2015) . These problems can be reduced by smart charging which can be implemented by several methods including the adjustment in price of charging. In order to facilitate the interactions between the ensembles of PEVs and the electric utility an aggregation agent would be required.

An entity called the "Aggregator" can aggregate the demand of large number of PEVs and buy electricity from the electric utility on their behalf (Sarker, Dvorkin, \& Ortega-Vazquez, Sept. 2016). The aggregator can collect trip information from PEVs to determine the optimal charging schedules for each PEV so as not to exceed the limits of the electric network.

Two main smart charging schemes have been proposed in the literatures: centralized and decentralized charging approaches (Vayá \& Andersson, 2015).

In the centralized charging scheme, the PEVs charging schedule is fully decided by the aggregator without any contribution from the PEVs owner. This approach was presented in (Foster \& Caramanis, Aug. 2013) where it developed a new bidding strategy (using mathematical programming) for the EV aggregator to operate in hour-ahead (real time) markets and show (using data from US power exchange) that it outperforms typical benchmarks by up to $15 \%$ (in cost reduction for the EVs).

The work in (Vayá \& Andersson, 2011) proposed a smart charging scheme based on Locational Marginal Pricing (LMP) for a day-ahead market to minimize charging costs, while satisfying the EVs' demand for electricity, the simulation based on data from German and Austrian distribution operators' prices. The work in (Jabalameli, Su, \& Ghosh, Sept. 2019), proposed a PEV charging coordination strategy based on heuristic genetic algorithm to maximize the benefit of the aggregator while considering transformer loading and bus voltage profiles. Also the work in (Long, Tang, \& Jia, 2017) focused on minimizing the charging costs of PEVs using multi-scale event-based optimization and defining a series of macro events to determine the number of PEVs to be charged for each aggregator. However, the drawback of centralized charging is minimizing PEVs owner welfare as customers don't have any contribution in charging decisions.

On the other hand, the decentralized charging allows the decisions to be taken locally by the PEVs owners. A decentralized approach was presented in (Esmaili \& Goldoust, 2015) to minimize the cost of purchasing energy for PEVs at households while minimizing the grid 
energy losses over the charging period. However, this study did not consider the stochastic nature of the driving patterns of PEVs. Another study in (Sarker, Ortega-Vazquez, \& Kirschen, May 2015) discussed the models where an aggregator attempts to maximize its benefits while allowing the PEVs owners to choose their charging profiles based on the pricing signals by simulating the PEV driving patterns based on historical data. In (Shafiekhah, et al., 2016) and (Sadati, Moshtagh, Shafie-khah, \& P.S.Catalão, July 2018), two models were developed to achieve optimal demand response of PEVs in a PL in both pricebased and incentive-based demand responses.

Nevertheless, these studies focused on maximizing the benefit of the aggregator without considering the benefits for the PEVs owners. The work in (Akhavan-Rezai, Shaaban, ElSaadany, \& Karray, June 2016) developed an online decision-making strategy which enables aggregators in public PLs to dynamically manage the charging of PEVs. The strategy was based on prioritizing PEVs in order to determine the order in which they are charged. The work (Gerding, Stein, Robu, \& Zhao, 2013) proposed a two-sided market (between charging points and EVs) at which the agents report their preferences and their value for the electricity, and the charging point's report their availability and costs, and then, they are allocated the slot that maximizes the difference between their value and the sellers' cost. However, the driving behaviors are not considered as only $100 \mathrm{EVs}$ are used to test this technique.

Although the behavior of PEVs has been studied in the literatures, to the best of our knowledge, a decentralized charging approach to control the charging behavior of PEVs based on their optimal response to the day-ahead charging prices in a PL considering the uncertainties accompanied with the driving behavior of the PEVs have not yet been addressed. Hence, the contributions of this paper can be summarized as follows:

- Modeling of uncertainness of PEVs driving behavior in parking lots

- Development a decentralized charging strategy to minimize PEVs charging costs in parking lots using two different charging prices, RTP and TOU to ensure that any overload of the electric distribution feeder connected to the PL is mitigated.

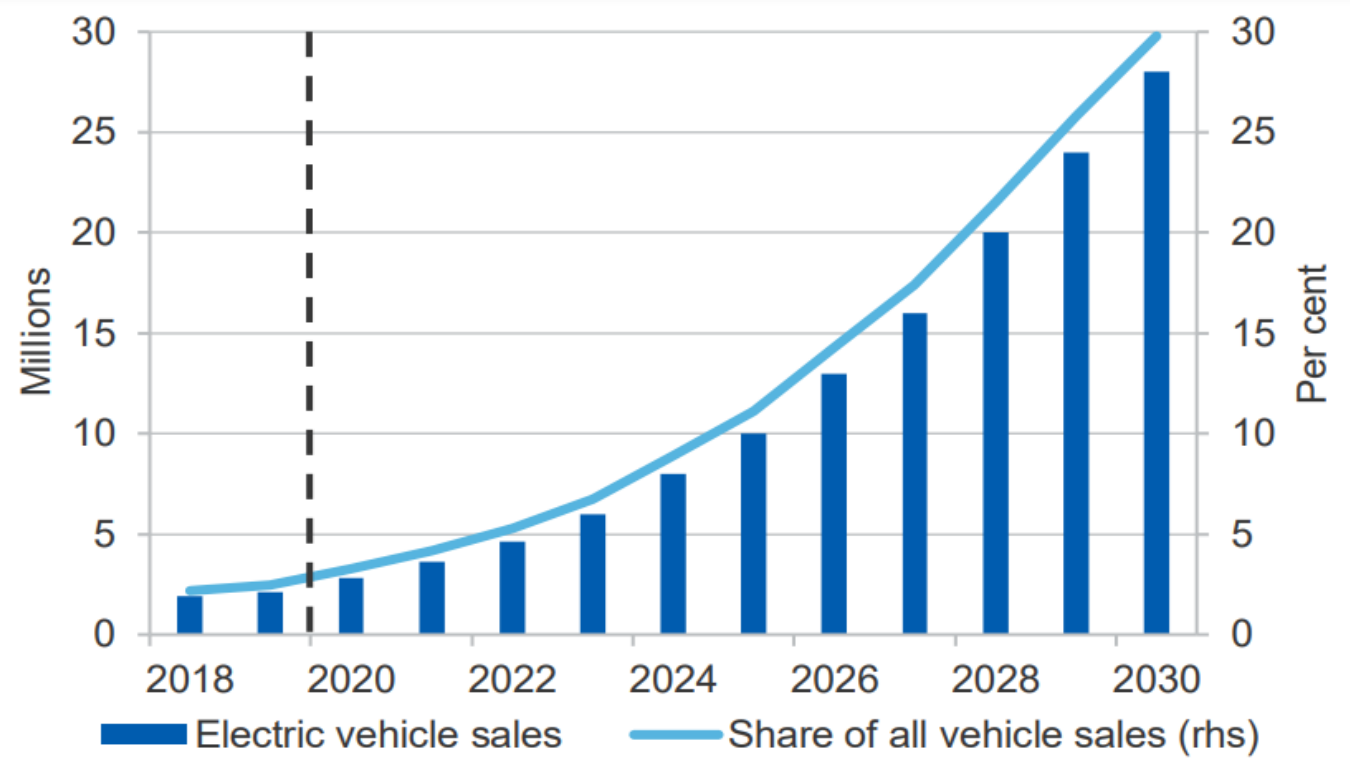

Figure (1) the projected PEVs world market from 2018 to 2030

\section{UNCERTAINTY OF THE DRIVING BEHAVIOR}

Assessing the impacts of PEVs on distribution systems requires an accurate determination of their chronological charging profiles. However, there are several uncertainties in the driving behavior of PEVs that impact the charging process. These include the arrival time, departure 
time and battery state of charge (SoC). These uncertainties complicate the precise estimation of the total demand of a PL at different times of the day. To overcome this issue, Monte Carlo (MC) simulation (Kalos \& Whitlock, 2008) can be used. MC simulation is a computational technique based on the use of random numbers and probability theory to solve problems of a stochastic nature. In this case, the stochastic inputs of the system being analyzed are represented by probability distributions. Hence, the simulations are run several times, each time using a different randomly selected set of inputs (generated from the predetermined probability distributions). For each trial of the simulation, the output of the trial is stored, and hence, the statistical behaviors of the outputs are obtained after completing all the trials. The flow chart describing the MC simulation in this study is shown in Figure 2. The first step is to initialize the simulation by the PEVs parameters, including the battery capacity, charging level, number of PEVs. In addition, the number of simulation trials, number of time segments in a day and the driver's survey data should be loaded in this step. For each trial, the arrival time, departure time and SoC of each PEV are estimated from the probability distributions as shown in Figure 3. The data are explored from survey of real driving behavior in PL so non sequential Monte Carlo is considered to simulate the states of the system over the specific duration of its live to estimate driving pattern by using the probability distributions generated for arrival time, departure time and battery state of charge (SoC).

This allows computing the charging profile for each PEV during the day. After constructing the charging profile for all PEVs in the PL, these are aggregated and added to obtain the load profile of the PL. 


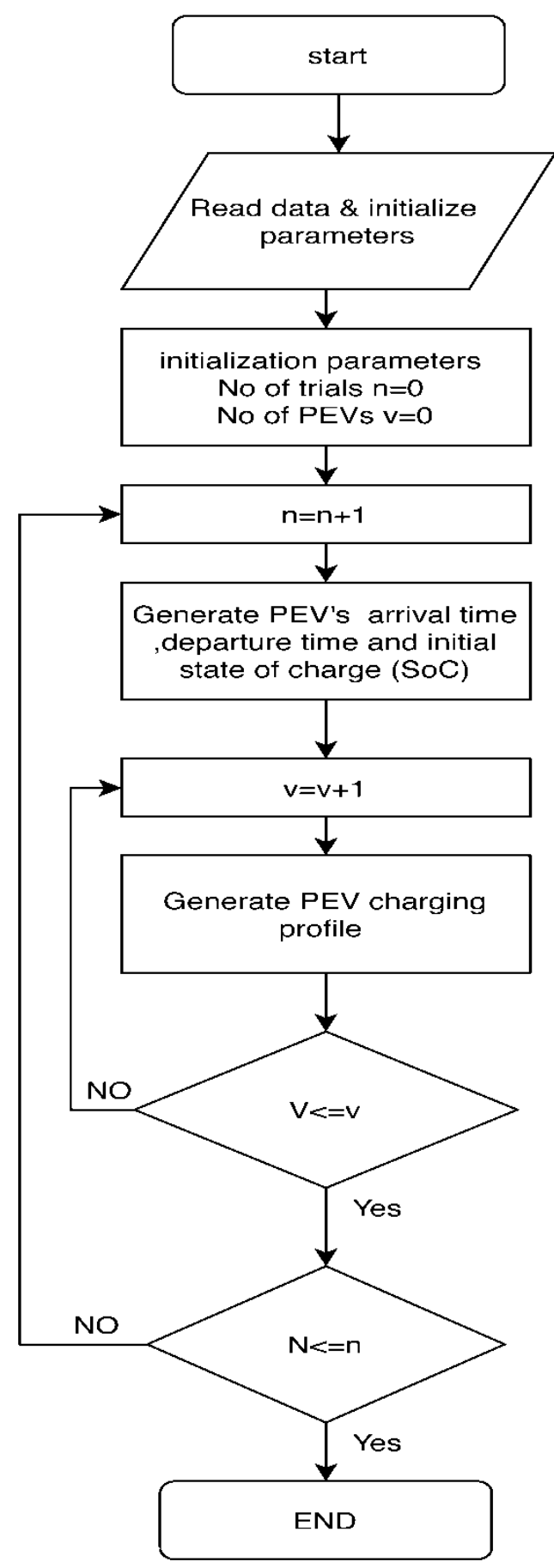

Figure (2) Monte Carlo simulation flow chart 


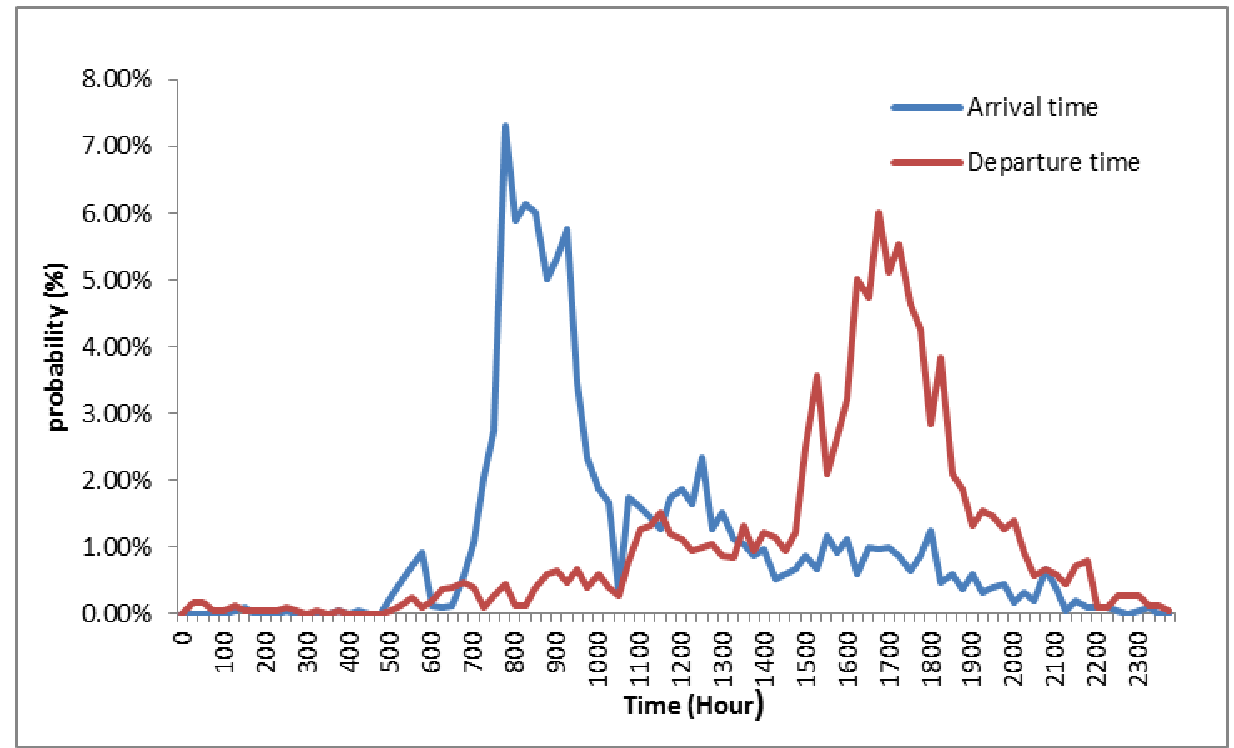

Figure (3) Probability distribution functions for arrival and departure time

\section{DECENTRALIZED CHARGING STRATEGY}

Uncontrolled charging is the most common method used in charging systems nowadays. In this case the PEVs are charged up to their maximum required capacity. PEVs start charging as soon as they park until their batteries are full or until they are leave the PL. As mentioned before, this might lead to operational problems in the electric network due to the possible overloading of the feeder. The smart decentralized charging strategy proposed in this paper is based on controlling the charging of PEVs using pricing signals received from the aggregator. In this case, the PEVs owners can decide their charging profiles to achieve the minimum possible charging cost. The role of the aggregator in this strategy is to decide the charging prices for the 24-hour period and receive the charging requests of the PEVs owners. The charging profile of the PEVs in the PL calculated over the time-horizon is formulated as a MILP optimization problem as follows:

$$
\begin{aligned}
& \min \Delta \mathrm{t} \sum_{(h \in T)}\left(\pi_{h}^{\mathrm{ch}} \times \mathrm{P}_{\mathrm{v}, \mathrm{h}}^{\mathrm{ch}}\right) \quad \forall \mathrm{v} \in \mathrm{V}, \forall \mathrm{h} \in \mathrm{T} \\
& \text { Subjected to }
\end{aligned}
$$

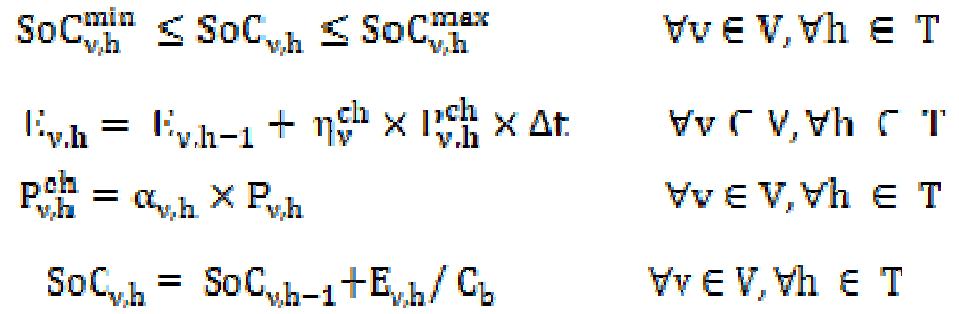

The aggregator sends the forecasted retail day-ahead prices $\left(\pi_{\mathrm{h}}^{\mathrm{ch}}\right)$ during each time interval $(\mathrm{h})$ to each PEV (v) where ( $t$ ) is an index to the set of time periods (T). The objective function in Equation (1) seeks to minimize the charging cost for each PEV. The PEVs are modeled as storage devices that can charge their batteries from the grid. Hence, Equation (2) ensures that the SoC of each PEV during each time interval is between the minimum SoC ( $\mathrm{SoC}_{\mathrm{v}, \mathrm{h}}^{\min }$ ) and its maximum SoC ( $\operatorname{SoC}_{\mathrm{v}, \mathrm{h}}^{\max }$ ). Equation (3) ensures that the energy of each PEV during each time interval $\left(E_{v, h}\right)$ is a function of its energy in the previous interval $\left(E_{v, h-1}\right)$, the charge power $\left(P_{v, h}^{\mathrm{ch}}\right)$ and the charging efficiency $\left(\eta_{v}^{\mathrm{eh}}\right)$. The PEV availability $\left(\alpha_{v, h}\right)$ in Equation (4) is a binary variable which indicates the charging status of each PEV (0 or 1$)$ during each time 
interval. This allows the PEV to choose which it's charging intervals. , Finally, Equation (5) determines the SoC of each PEV at each time interval as function of its $\mathrm{SoC}$ in the previous interval where $\mathrm{C}_{\mathrm{b}}$ is the battery capacity.

\section{SALP SWARM ALGORITHM (SSA)}

The mathematical model of swarming behavior of salp chains starts with dividing the population in two groups, namely the leader and the follower. The leader salp is always at the front of the salp chain to guide the swarm and the rest follows it (Mirjalili, H.Gandomi, Mirjalili, \& Saremi, 2017). In the search space, there is a food source as each swarm is targeting at and is called TF. The location updating equation for the leader salp with respect to the target food is given as.

$$
\mathcal{X}_{j}^{1}=\left\{\begin{array}{ll}
T F_{j}+C_{1}\left(C_{2}\left(u b_{j}-l b_{j}\right)+l b_{j}\right) & C_{3} \geq 0 \\
T F_{j}-C_{1}\left(C_{2}\left(u b_{j}-l b_{j}\right)+l b_{j}\right) & C_{3}<0
\end{array}\right\}
$$

Here, $x_{j}^{1}$ represents the location of the leader salp in the $j$ th dimension, $T F_{j}$ represents the location of the target food in the $j$ th dimension, $C_{1}, C_{2}$, and $C_{3}$ are random numbers, $u b_{j}$ and $l b_{j}$ are upper and lower bounds in the $j$ th dimension, respectively. The coefficient $C_{1}$ is balancing the exploration and exploitation phases of the algorithm. Therefore, it is considered as the most important parameter of the SSA and given as in

$$
C_{1}=2 e^{-\left(\frac{4 m}{M}\right)^{2}}
$$

Here, $m$ represents the current iteration, and $M$ represents the total number of iterations, which is chosen as 1000 in this paper. Both random numbers $C_{2}$ and $C_{3}$ are homogeneously produced in the range of $[0,1]$. To update the location of each follower salp with respect to the one that it follows is given in

$$
x_{j}^{i}=\frac{1}{2}\left(x_{j}^{i}+x_{j}^{i-1}\right) \quad \forall i \geq 2
$$

Equation (8) shows that each salp follows its leader to form a salp chain. Here, $x_{j}^{i}$ represent the location of the $i t h$ follower salp in $i$ th dimension. The initial locations of all salps and behavior of salps chain is modelled as shown in Figure 4 (Barik \& Das, 2018). 


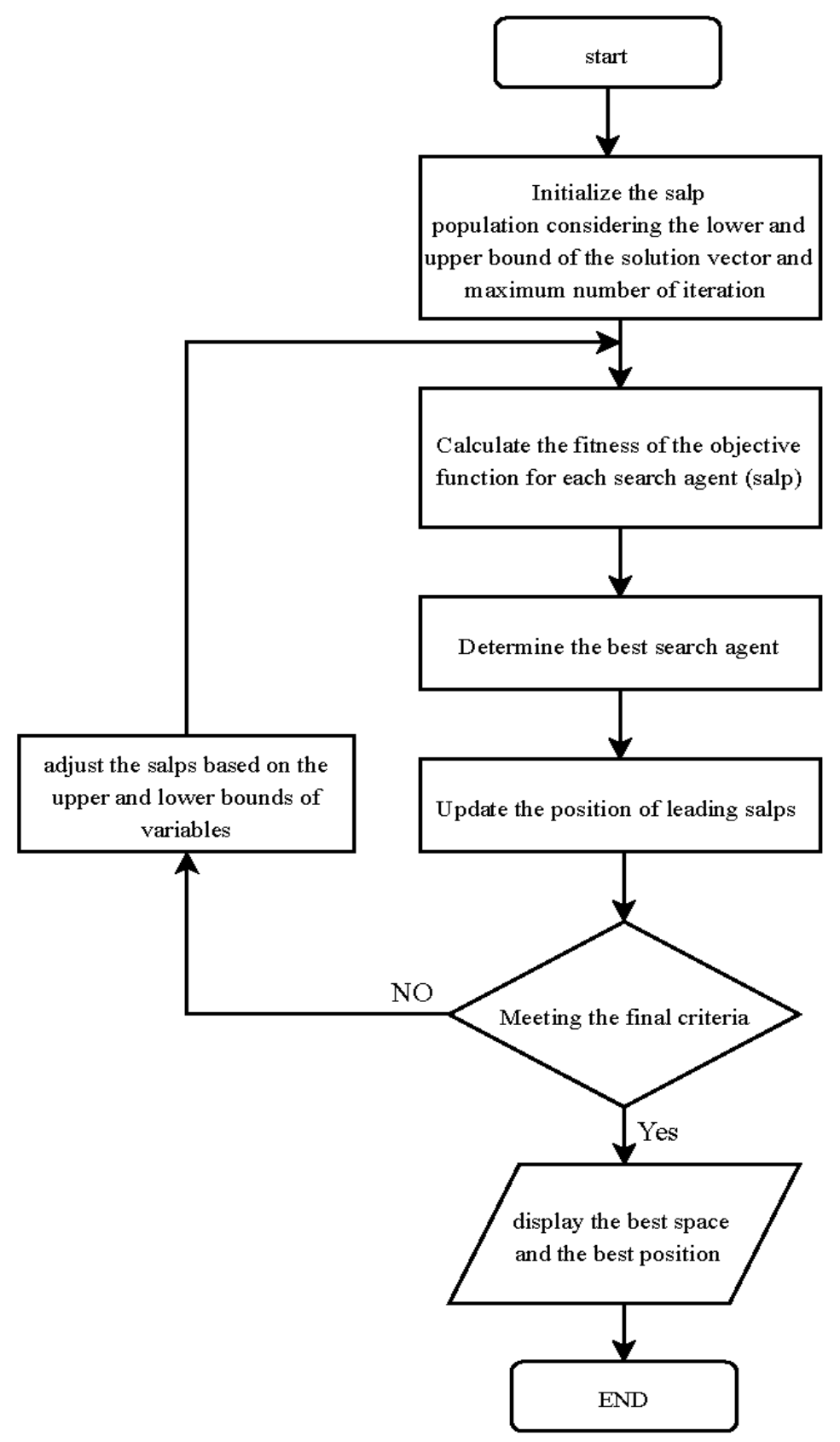

Figure (4) Salp Swarm Algorithm flow chart

\section{SIMULATIONS AND RESULTS}

The proposed charging strategy is tested on the standard IEEE 15-bus, $50 \mathrm{~Hz}$ radial distribution system over a 24-h period divided into 15-minute intervals. The PL is assumed to be installed at bus 12 as shown in Figure 5. The line parameters and load data are listed in Table 1. The data are based on 30MVA and $11 \mathrm{kV}$ bases.

In this paper, for resolving the optimization problem which is a mixed-integer linear programming (MILP) problem the SSA and PSO was carried out in MATLAB.

A scenario tree of all uncertainties is generated by the Monte Carlo method. The stopping criterion of the simulation of Monte Carlo is to reach 1000 trials. 
This number is selected, because it was seen that more simulations does not affect the result significantly after this number of trials is reached. The simulation is implemented in a laptop with Core i7 up to $2.2 \mathrm{GHz} \mathrm{CPU}, 8 \mathrm{~GB}$ RAM (DDR4), and $4 \mathrm{MB}$ Cash.

Figure (5) 15-bus Radial Distribution System

Table 1. Line Parameters And Load Data Of 15-Bus Radial Distribution System.

\begin{tabular}{|c|c|c|c|c|c|}
\hline $\begin{array}{c}\text { Fro } \\
\text { m } \\
\text { Bus }\end{array}$ & $\begin{array}{c}\text { To } \\
\mathrm{Bu} \\
\mathrm{S}\end{array}$ & $\begin{array}{c}\text { R } \\
\text { P.U }\end{array}$ & $\begin{array}{c}X \\
\text { P.U }\end{array}$ & $\begin{array}{c}\text { P } \\
\text { P.U }\end{array}$ & $\begin{array}{l}\text { Q } \\
\text { P.U }\end{array}$ \\
\hline 1 & 2 & $\begin{array}{c}0.0031 \\
5\end{array}$ & $\begin{array}{c}0.07520 \\
7\end{array}$ & $\begin{array}{c}0.020 \\
8\end{array}$ & $\begin{array}{c}0.002 \\
1\end{array}$ \\
\hline 2 & 3 & $\begin{array}{c}0.0003 \\
3\end{array}$ & $\begin{array}{c}0.00184 \\
9\end{array}$ & $\begin{array}{c}0.049 \\
5\end{array}$ & $\begin{array}{c}0.005 \\
1\end{array}$ \\
\hline 3 & 4 & $\begin{array}{c}0.0066 \\
7\end{array}$ & $\begin{array}{c}0.03080 \\
8\end{array}$ & $\begin{array}{c}0.095 \\
8\end{array}$ & $\begin{array}{c}0.009 \\
8\end{array}$ \\
\hline 4 & 5 & $\begin{array}{c}0.0057 \\
9\end{array}$ & $\begin{array}{c}0.01494 \\
9\end{array}$ & $\begin{array}{c}0.042 \\
2\end{array}$ & $\begin{array}{c}0.004 \\
5\end{array}$ \\
\hline 5 & 6 & $\begin{array}{c}0.0141 \\
4\end{array}$ & $\begin{array}{c}0.03654 \\
9\end{array}$ & $\begin{array}{c}0.013 \\
3\end{array}$ & $\begin{array}{c}0.001 \\
2\end{array}$ \\
\hline 6 & 7 & 0.008 & $\begin{array}{c}0.03696 \\
1\end{array}$ & $\begin{array}{c}0.063 \\
8\end{array}$ & $\begin{array}{c}0.006 \\
6\end{array}$ \\
\hline 7 & 8 & 0.009 & $\begin{array}{c}0.04157 \\
5\end{array}$ & $\begin{array}{c}0.032 \\
3\end{array}$ & $\begin{array}{c}0.003 \\
3\end{array}$ \\
\hline 8 & 9 & 0.007 & $\begin{array}{c}0.03234 \\
6\end{array}$ & $\begin{array}{c}0.021 \\
3\end{array}$ & $\begin{array}{c}0.002 \\
2\end{array}$ \\
\hline 9 & 10 & $\begin{array}{c}0.0036 \\
7\end{array}$ & 0.01694 & 0.028 & $\begin{array}{c}0.002 \\
9\end{array}$ \\
\hline 10 & 11 & 0.009 & $\begin{array}{c}0.04157 \\
5\end{array}$ & 0.217 & $\begin{array}{c}0.002 \\
2\end{array}$ \\
\hline 3 & 12 & 0.0275 & $\begin{array}{c}0.12704 \\
3\end{array}$ & $\begin{array}{c}0.013 \\
2\end{array}$ & $\begin{array}{c}0.001 \\
4\end{array}$ \\
\hline 12 & 13 & 0.0315 & $\begin{array}{c}0.08140 \\
5\end{array}$ & $\begin{array}{c}0.002 \\
9\end{array}$ & $\begin{array}{c}0.000 \\
3\end{array}$ \\
\hline 13 & 14 & $\begin{array}{c}0.0396 \\
5\end{array}$ & $\begin{array}{c}0.10298 \\
4\end{array}$ & $\begin{array}{c}0.016 \\
1\end{array}$ & $\begin{array}{c}0.001 \\
6\end{array}$ \\
\hline 14 & 15 & $\begin{array}{c}0.0106 \\
1\end{array}$ & $\begin{array}{c}0.00415 \\
3\end{array}$ & $\begin{array}{c}0.013 \\
9\end{array}$ & $\begin{array}{c}0.001 \\
4\end{array}$ \\
\hline
\end{tabular}

This paper uses the Caltech campus data set to model the PEVs' behavior using the MC simulation to calculate the energy required for each session and hence, obtain the PL charging profile for a typical weekday.

The ACN-Data set is a dynamic dataset of workplace PEVs charging which currently includes over 30,000 sessions collected from two PLs located in California (EV Research@ Caltech, 2020) (Lee, Li, \& Low, 2019). The ACN data set have PEVs data for Caltech campus PL and JPL site PL.

It is assumed that 100 PEVs with different driving patterns can be parked in the PL in a typical day. The charge efficiencies of PEV batteries are assumed to be $90 \%$ with a capacity of $30 \mathrm{kWh}$. The SoC can range only between a minimum of $15 \%$ and a maximum of $95 \%$. According the charging levels, the Society of Automotive Engineers (SAE) identifies three charging levels for PEVs charging as shown in Table 2 (Bohn, Agsten, Dubey, \& Santoso, Apr. 2015). It is assumed that all PEV batteries are charged using $7.2 \mathrm{~kW}$ level-2 rapid chargers with AC connectors SAEJ1772 (Longo, et al., 2016). 
This paper compares between two types of optimization techniques SSA and PSO used to examine three test cases. SSA convergence criteria is reaching 1000 iterations or the tolerance between the present solution and the previous solutions after the $100^{\text {th }}$ iteration is lower than $10^{-8}$. The convergence characteristics of SSA and PSO methods are shown in Figure 6. From the convergence plot, the PSO technique has better convergence rate to reach the optimal solution (46 iterations) than SSA (61 iterations) but the SSA technique has better simulation speed (13.083 seconds) than PSO (33.7 seconds).

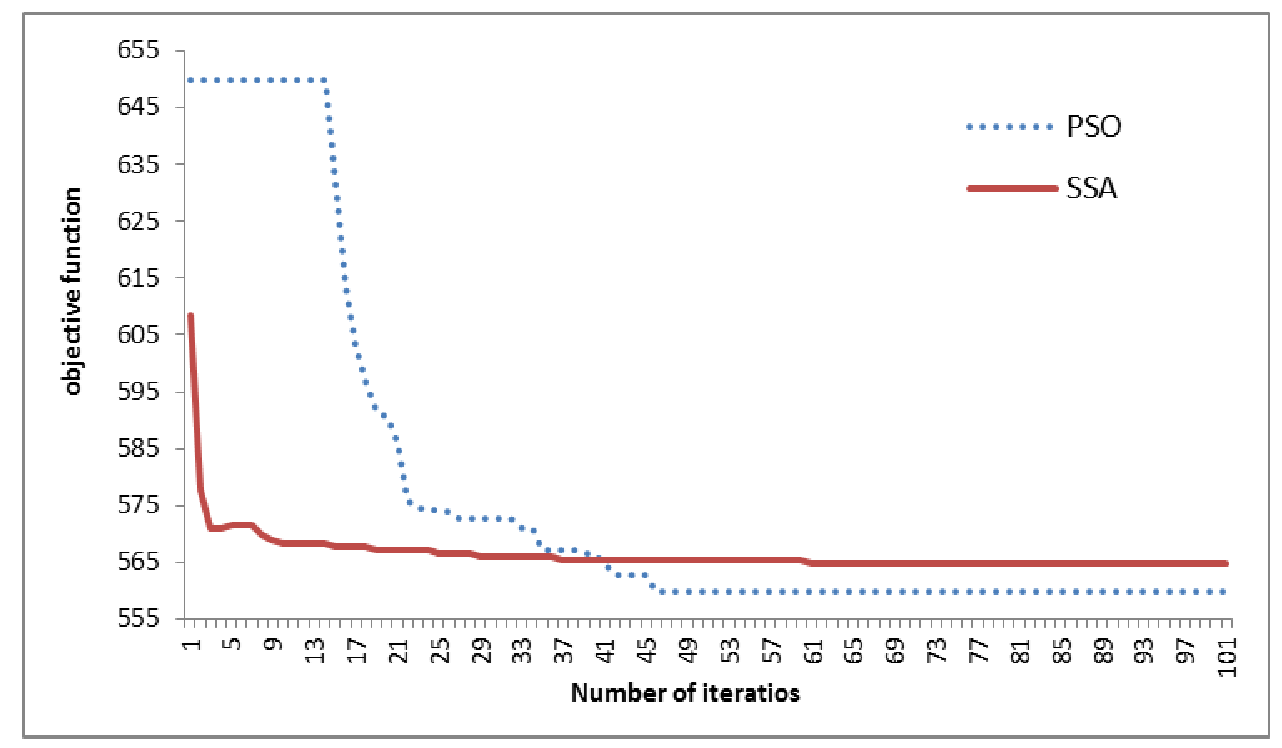

Figure (6) Convergence curve of PSO and SSA techniques.

Table 2. Pev Charging Levels And Charger Specifications .

\begin{tabular}{|l|l|l|}
\hline Charging level Type & Voltage level & Power level \\
\hline Level-1 & 120 VAC & Up to $1.8 \mathrm{KW}$ \\
\hline Level-2 & $208-240$ VAC & Up to $19.2 \mathrm{KW}$ \\
\hline Level-3 or DC charging & 480 VDC & $50 \mathrm{~kW}$ to $150 \mathrm{~kW}$ \\
\hline
\end{tabular}

The three cases are as following: Case 1 considers the uncontrolled charging while Case 2 and Case 3 examine the TOU pricing and RTP, respectively.

The TOU and RTP pricing profiles used in this paper are displayed in Figure 7, (Sadati, Moshtagh, Shafie-khah, \& P.S.Catalão, July 2018) (Consulting, 2020). 


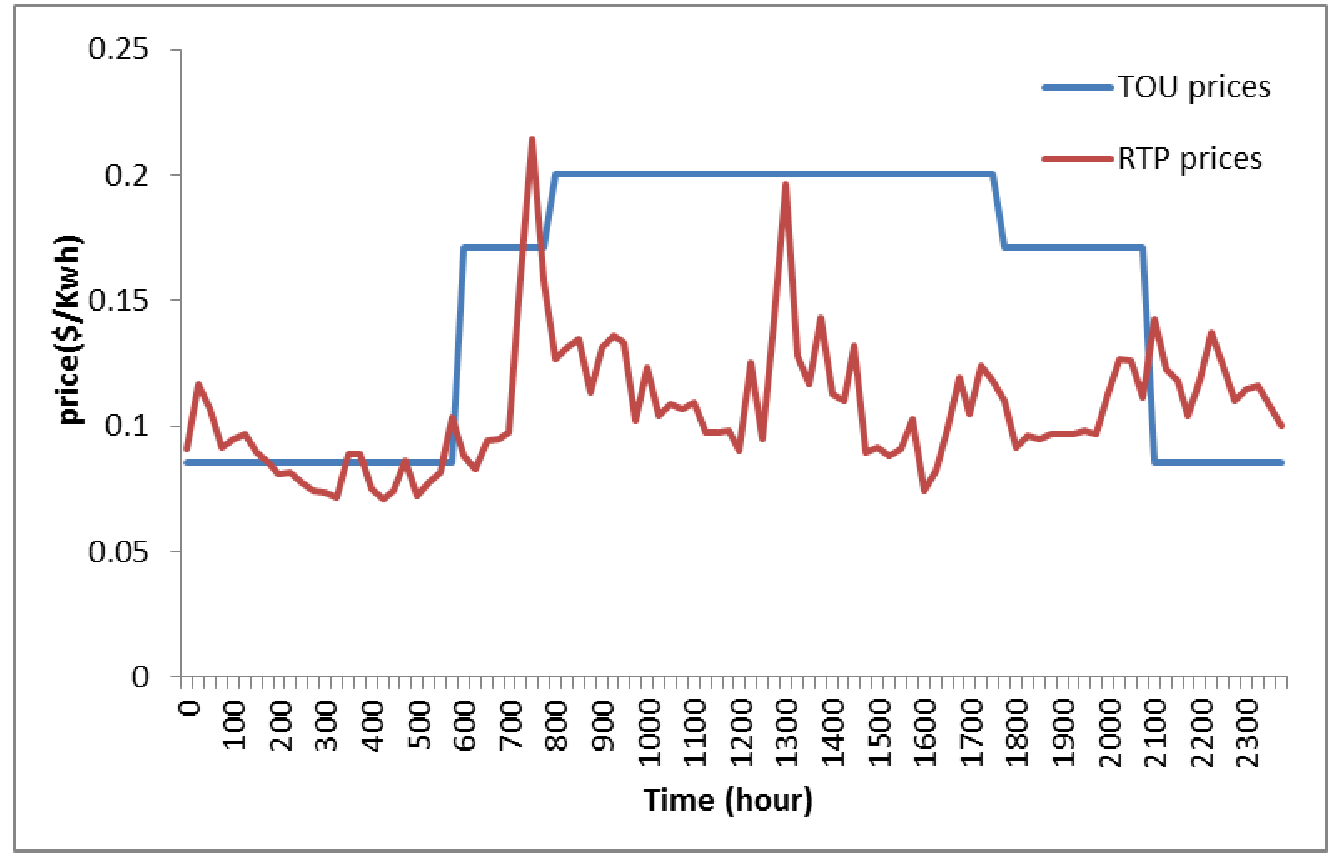

Figure (7) TOU and RTP pricing profiles

\subsection{UNCONTROLLED CHARGING}

The uncontrolled charging of PEVs will lead to the charging profile of the PL shown in Figure 8. In this case, the peak demand of the PL is $150 \mathrm{~kW}$. The peak demand of the bus considering the PL and the base load of the Bus 12 (Nassar \& Salama, 2015) is $447 \mathrm{~kW}$ at 9:00 which exceeds the line capacity as shown Figure 9, 11

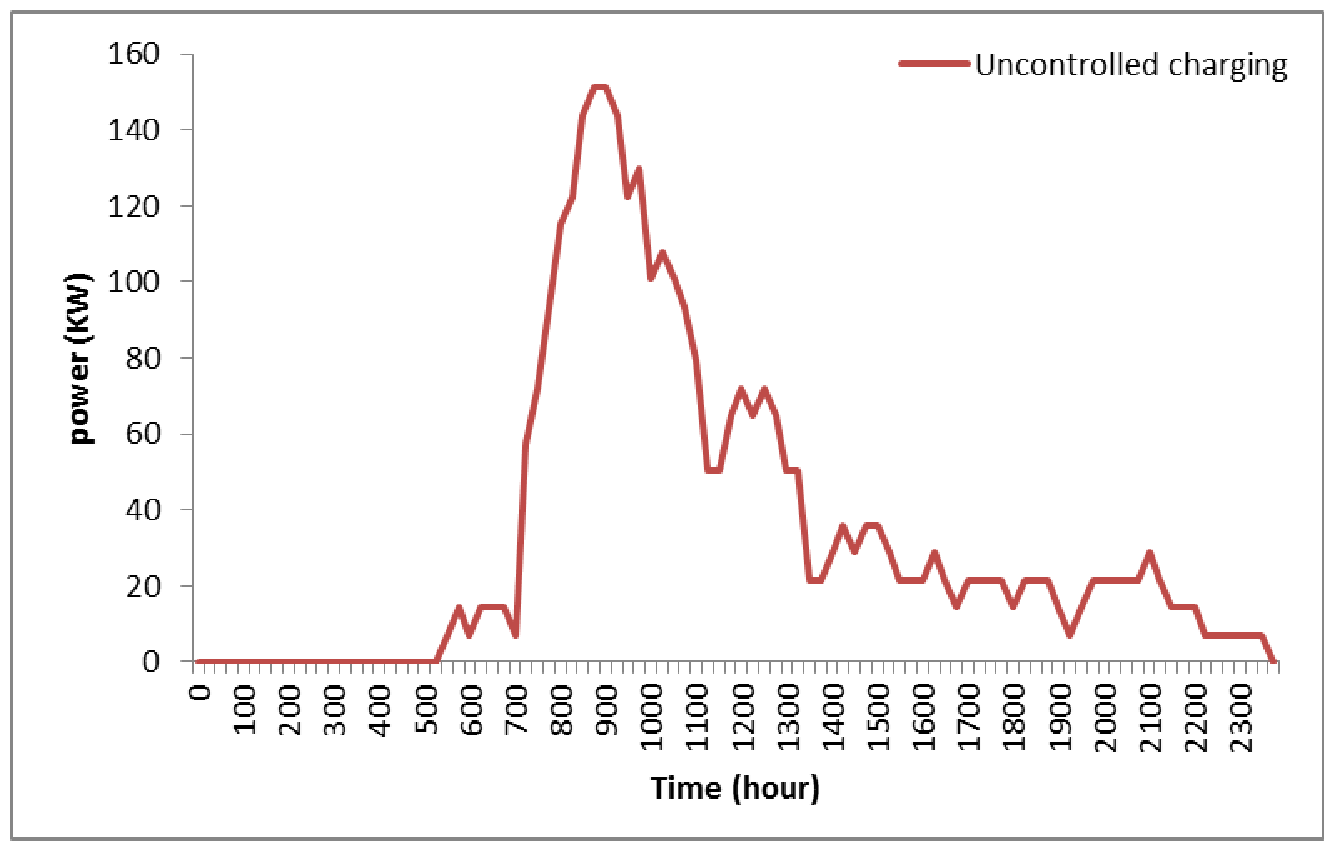

Figure (8) PEVs uncontrolled charging profile in Parking lot 


\subsection{SMART CHARGING USING TOU PRICING:}

In this case, the TOU pricing is investigated and compared against the uncontrolled charging. First by SSA method, the charging energy of the PL over $24 \mathrm{~h}$ is $626.4 \mathrm{kWh}$ with peak power $86.4 \mathrm{~kW}$ at 17:45 and total cost 141.34 \$/day for all PEVs.

Second by PSO method, the charging energy of the PL over $24 \mathrm{~h}$ is $626.4 \mathrm{kWh}$ with peak power $100.8 \mathrm{~kW}$ at 13:30 with total cost of 139.9 \$/day for all PEVs as shown in table 3. Figure 9 shows the PL charging profile for these cases as compared to the uncontrolled case. It is clear from the figure that the TOU pricing was able to avoid the peak loading at 9:00 that resulted from the uncontrolled charging. Moreover, the charging profile during peak hours is almost smooth with no spikes over the whole period. Figure 10 shows the behavior of a PEV for the uncontrolled charging and its behavior in case of smart charging using TOU pricing.

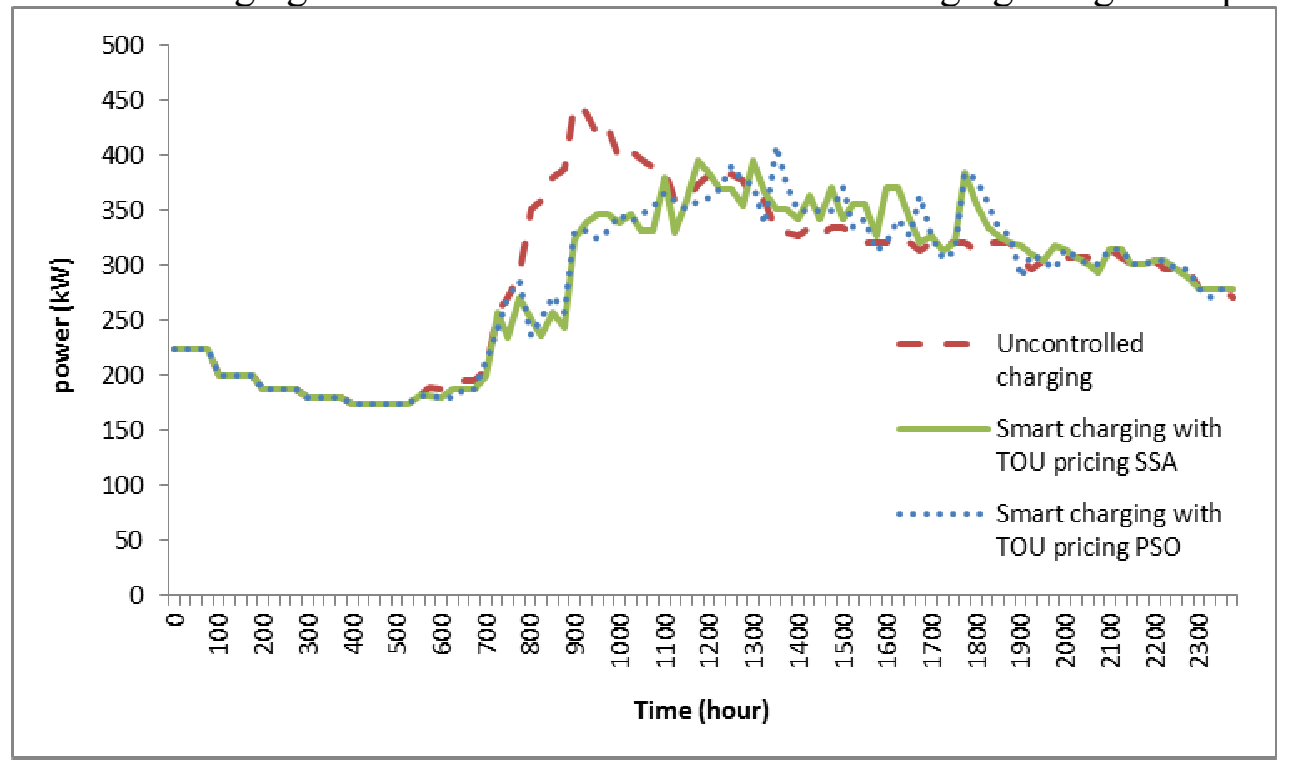

Figure (9) Comparison between uncontrolled charging profile and smart charging profile with RTP using SSA and PSO

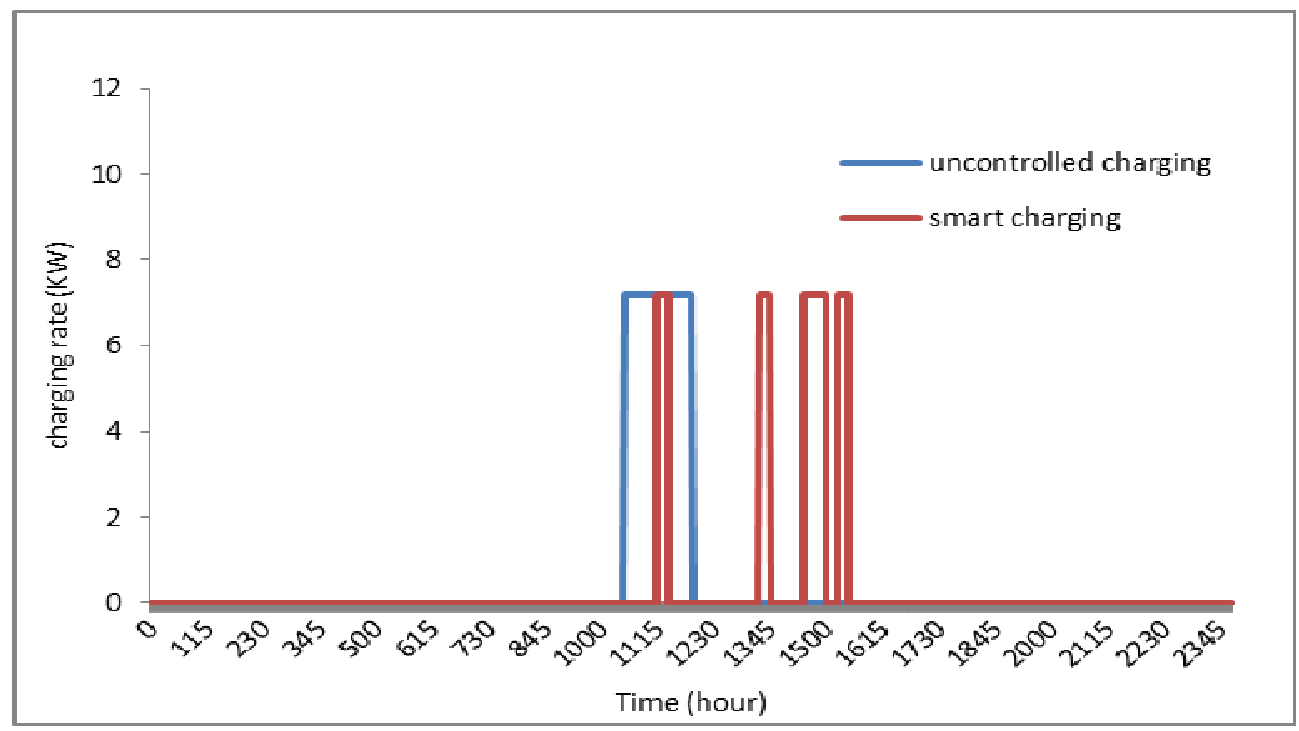

Figure (10) Uncontrolled charging and smart charging profile for Typical PEV 


\subsection{SMART CHARGING USING RTP PRICING:}

This case investigates the use of smart charging using RTP pricing. First by SSA method, the solution of the optimization problem results in charging energy over $24 \mathrm{~h}$ of $626.4 \mathrm{kWh}$ with peak power $252 \mathrm{~kW}$ at 14:45 and total cost of 59.4 \$/day for all PEVs. Second by PSO method, the solution of the optimization problem results in charging energy over $24 \mathrm{~h}$ of 626.4 $\mathrm{kWh}$ with peak power $331.2 \mathrm{~kW}$ at 16:00 and total cost of 57.6 \$/day for all PEVs as shown in table 3.

These costs are less than that of Case 2 as the RTP pricing provides more flexibility for the PEVs owners to choose the charging periods that ensures the minimum possible cost during their stay in the PL. Figure 11 illustrates the difference between uncontrolled charging and the proposed smart charging with RTP pricing. The figure shows that the peak at 9:00 am due to uncontrolled charging has been disappeared using the RTP pricing. However, the PEVs took advantage of the low prices of RTP at 12:00 and from 15:00 till 16:00. Thus, the charging from the PL has increased enormously during these periods. In SSA method the feeder loading at Bus 12 reached $491.6 \mathrm{~kW}$ (PEVs charging power $180 \mathrm{~kW}$ ) at 12:00 and reached $551 \mathrm{KW}$ (PEVs charging power $252 \mathrm{~kW}$ ) at 14:45. In PSO method the feeder loading at Bus 12 reached $534.8 \mathrm{~kW}$ (PEVs charging power $223.2 \mathrm{~kW}$ ) at 12:00 and reached 630.2 KW (PEVs charging power $331.2 \mathrm{~kW}$ ) at 16:00.

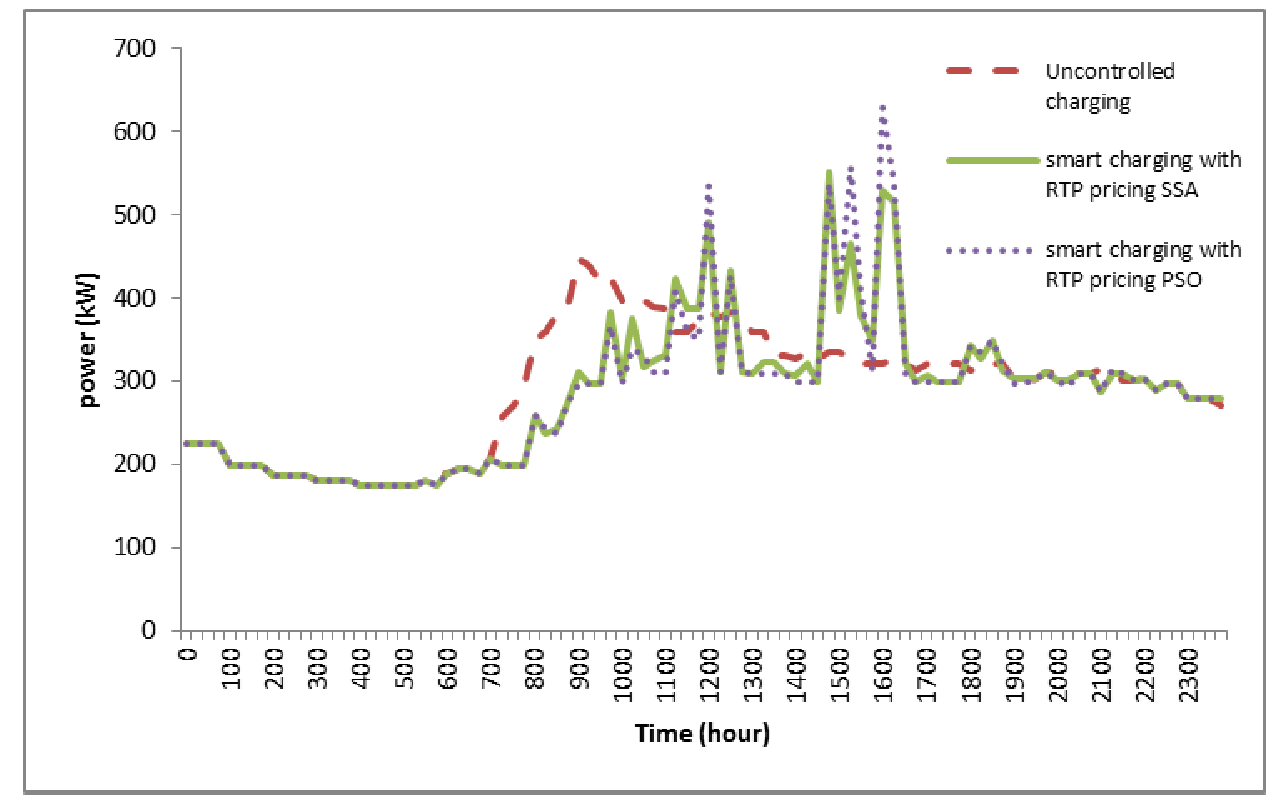

Figure (11) Comparison between uncontrolled charging profile and smart charging profile with RTP using SSA and PSO

Table 3. Results of total charging cost using TOU and RTP tariffs for SSA and PSO techniques (\$/day).

\begin{tabular}{|l|c|c|}
\hline \multirow{2}{*}{ Algorithms } & \multicolumn{2}{|c|}{ Tariff type } \\
\cline { 2 - 3 } & TOU (time of use) & RTP (Real time pricing) \\
\hline SSA & 141.34 & 59.4 \\
\hline PSO & 139.9 & 57.6 \\
\hline
\end{tabular}

\section{CONCLUSIONS}

In this paper, a decentralized smart charging strategy is proposed. The strategy allows the PEVs owners to decide their charging profiles in a PL. The aggregator provides suitable pricing signals to ensure the required profit and avoid feeder overloading. TOU and RTP pricing signals are investigated and compared in this paper against the uncontrolled charging which leads to overloads in the system. The results show that the RTP is more flexible than 
TOU as it gives the PEVs owners the opportunity to lower their charging prices. However, this pricing strategy might lead to system overloads at times where the prices are low. Comparing with the TOU pricing which shows that it can avoid the system overloads if properly designed. However, the charging prices for PEVs owners are increased as compared to the RTP. On other hand novel approach called salp swarm algorithm (SSA) is proposed in this paper gives very close results comparing with PSO method despite SSA technique has simulation speed higher than PSO technique.

\section{REFERENCES}

1. Rajakaruna, S., Shahnia, F., \& Ghosh, A. (2016). Plug in electric vehicles in smart grids. Springer.

2. (2020). Annual Energy Outlook 2020. U.S. Department of Energy.

3. Bloomberg. (2019). https://about.bnef.com/electric-vehicle-outlook/. (Bloomberg)

4. Shareef, H., Islam, M., \& Mohamed, A. (2016). A review of the stage-of-the-art Charging technologies, placement methodologies, and impacts of electric vehicles. Renew. Sustain. Energy Rev. 64, 403-420.

5. Yong, J. Y., Ramachandaramurthy, V. K., Tan, K. M., \& Mithulananthan, N. (2015). A review on the state-of-the-art technologies of electric vehicle, its impacts and prospects. Renew. Sustain. Energy Rev. 49, 365-385.

6. Hoog, J. d., Alpcan, T., Brazil, M., Thomas, D. A., \& Mareels, I. (2015). Optimal Charging of Electric Vehicles Taking Distribution Network Constraints Into Account. IEEE Trans. on Power Systems, 30, 365 - 375.

7. Sarker, M. R., Dvorkin, Y., \& Ortega-Vazquez, M. A. (Sept. 2016). Optimal Participation of an Electric Vehicle Aggregator in Day-Ahead Energy and Reserve Markets. IEEE Trans. on Power Systems, 31(5), 3506 - 3515.

8. Vayá, M. G., \& Andersson, G. (2015). Plug-in Electric Vehicle charging approaches: Centralized versus decentralized and strategic versus cooperative. IEEE Eindhoven PowerTech.

9. J Foster, J. M., \& Caramanis, M. C. (Aug. 2013). Optimal Power Market Participation of Plug-In Electric Vehicles Pooled by Distribution Feeder. IEEE Transactions on Power Systems , 28(3), 2065 - 2076.

10. Vayá, M. G., \& Andersson, G. (2011). Locational Marginal Pricing based Smart Charging of Plug-In Hybrid Vehicle Fleets. smart energy strategies conf, 21-23.

11. Jabalameli, N., Su, X., \& Ghosh, A. (Sept. 2019). Online Centralized Charging Coordination of PEVs With Decentralized Var Discharging for Mitigation of Voltage Unbalance. IEEE Power and Energy Technology Systems Journal, 6(3), 152 - 161.

12. Long, T., Tang, J.-X., \& Jia, Q.-S. (2018). Multi-scale event-based optimization for matching uncertain wind supply with EV charging demand. 13th IEEE Conference on Automation Science and Engineering (CASE).

13. Esmaili, M., \& Goldoust, A. (2015). Multi-objective optimal charging of plug-in electric vehicles in unbalanced distribution networks. International Journal of Electrical Power \& Energy Systems, 73, 644-652.

14. Sarker, M. R., Ortega-Vazquez, M. A., \& Kirschen, D. S. (May 2015). Optimal Coordination and Scheduling of Demand Response via Monetary Incentives. IEEE Trans. on Smart Grid , 6(3), 1341 - 1352.

15. Shafie-khah, M., Heydarian-Forushani, E., Osório, G. J., Gil, F. A., \& Aghaei, J. ( Nov. 2016 ). Optimal Behavior of Electric Vehicle Parking Lots as Demand Response Aggregation Agents. IEEE Trans. on Smart Grid, 7(6), 2654 - 2665.

16. BagherSadati, 1. M., Moshtagh, J., Shafie-khah, M., \& P.S.Catalão, J. (July 2018). Smart distribution system operational scheduling considering electric vehicle parking lot and demand response programs. Electric Power Systems Research, 160, 404-418.

17. Akhavan-Rezai, E., Shaaban, M. F., El-Saadany, E. F., \& Karray, F. (June 2016). Online Intelligent Demand Management of Plug-In Electric Vehicles in Future Smart Parking Lots. IEEE Systems Journal , 10(2), 483 - 494. 
18. Gerding, E. H., Stein, S., Robu, V., Zhao, D., \& Jennings, N. R. (2013). Two-Sided Online Markets for Electric Vehicle Charging. Proc. Int. Conf. Auton., 989-996.

19. Kalos, M. H., \& Whitlock, P. A. (2008). Monte Carlo Methods, 2nd Edition.

20. Mirjalili, S. (2017). Salp Swarm Algorithm: A bio-inspired optimizer for engineering design problems. Advances in Engineering Software, 114, 163-191.

21. Barik, A. K., \& Das, D. C. (2018). Active power management of isolated renewable microgrid generating power from Rooftop solar arrays, sewage waters and solid urban wastes of a smart city using Salp swarm algorithm. Technologies for Smart-City Energy Security and Power (ICSESP).

22.EV Research@ Caltech. (2020). (Caltech) Retrieved from https://ev.caltech.edu/dataset

23. Lee, Z. J., Li, T., \& Low, S. H. (2019). ACN-Data: Analysis and Applications of an Open EV Charging Dataset. e-Energy '19: Proceedings of the Tenth ACM International Conference on Future Energy Systems, 139-149.

24. S Bohn, S., Agsten, M., Dubey, A., \& Santoso, S. (Apr. 2015). A Comparative Analysis of PEV Charging Impacts -An International Perspective. Proc. SAE Word Congr. Exhibit., Detroit, MI, USA, 1-10.

25. Longo, M., Zaninelli, D., Viola, F., Romano, P., Miceli, R., Caruso, M., \& Pellitteri, F. (May 2016). Recharge stations: A review. Eleventh International Conference on Ecological Vehicles and Renewable Energies (EVER).

26. Consulting, L. (2020). energy online. Retrieved from http://www.energyonline.com/Data/GenericData.aspx?DataId=22\&CAISO__DayAhead_Price

27. Nassar, M. E., \& Salama, M. M. (June 2015). A novel probabilistic load model and probabilistic power flow. IEEE 28th Canadian Conference on Electrical and Computer Engineering (CCECE). 